\title{
APASL clinical practice recommendation: how to treat HCV-infected patients with renal impairment?
}

\author{
Tatsuo Kanda ${ }^{1}$ - George K. K. Lau ${ }^{2}$ - Lai Wei ${ }^{3}$ - Mitsuhiko Moriyama ${ }^{1}$ Ming-Lung Yu ${ }^{4,5}$. Wang-Long Chuang ${ }^{5}$. \\ Alaaeldin Ibrahim $^{6}$. Cosmas Rinaldi Adithya Lesmana ${ }^{7,8}$. Jose Sollano ${ }^{9} \cdot$ Manoj Kumar $^{10}$. Ankur Jindal ${ }^{10}$. \\ Barjesh Chander Sharma ${ }^{11}$. Saeed S. Hamid ${ }^{12}$ - A. Kadir Dokmeci ${ }^{13} \cdot$ Mamun-Al-Mahtab $^{14}$. \\ Geofferey W. McCaughan ${ }^{15}$. Jafri Wasim ${ }^{12}$. Darrell H. G. Crawford ${ }^{16}$. Jia-Horng Kao ${ }^{17}$. Osamu Yokosuka ${ }^{18}$. \\ Shiv Kumar Sarin ${ }^{10} \cdot$ Masao Omata ${ }^{19,20}$
}

Received: 9 August 2018 / Accepted: 19 November 2018 / Published online: 11 December 2018

(c) The Author(s) 2018

\begin{abstract}
Chronic hepatitis $\mathrm{C}$ virus (HCV) infection is common among patients with chronic kidney disease (CKD) and those on hemodialysis due to nosocomial infections and past blood transfusions. While a majority of HCV-infected patients with end-stage renal disease are asymptomatic, some may ultimately experience decompensated liver diseases and hepatocellular carcinoma. Administration of a combination of elbasvir/grazoprevir for 12 weeks leads to high sustained virologic response (SVR) rates in patients with HCV genotypes (GTs) 1a, 1b or 4 and stage 4 or 5 CKD. Furthermore, a combination of glecaprevir/pibrentasvir for 8-16 weeks also results in high SVR rates in patients with all HCV GTs and stage 4 or 5 CKD. However, these regimens are contraindicated in the presence of advanced decompensated cirrhosis. Although sofosbuvir and/or ribavirin are not generally recommended for HCV-infected patients with severe renal impairment, sofosbuvir-based regimens may be appropriate for those with mild renal impairment. To eliminate HCV worldwide, HCV-infected patients with renal impairment should be treated with interferon-free therapies.
\end{abstract}

Keywords HCV $\cdot$ Renal impairment $\cdot$ DAA $\cdot$ SVR $\cdot$ Hemodialysis $\cdot$ Guideline

$\begin{array}{ll}\text { Abbreviations } \\ \text { HCV } & \text { Hepatitis C virus } \\ \text { GT } & \text { Genotype } \\ \text { HCC } & \text { Hepatocellular carcinoma } \\ \text { DAAs } & \text { Direct-acting antivirals } \\ \text { SVR } & \text { Sustained virological response } \\ \text { CKD } & \text { Chronic kidney disease }\end{array}$

\section{Introduction}

Hepatitis $\mathrm{C}$ virus (HCV) infection causes liver diseases including chronic hepatitis, cirrhosis and hepatocellular carcinoma (HCC), as well as, extrahepatic manifestations

Electronic supplementary material The online version of this article (https://doi.org/10.1007/s12072-018-9915-5) contains supplementary material, which is available to authorized users.

Masao Omata

momata-tky@umin.ac.jp

Extended author information available on the last page of the article
[1-3]. Chronic kidney disease (CKD) is one such extrahepatic manifestation of $\mathrm{HCV}$ infection [3]. $\mathrm{HCV}$ infection also causes cryoglobulinemia and cryoglobulin deposits on vascular endothelium, triggering vasculitis in organs such as the kidneys [4]. HCV-related nephropathy is a type I membranoproliferative glomerulonephritis, commonly in the context of type II mixed cryoglobulinemia [5].

Patients with end-stage renal diseases are at high risk for $\mathrm{HCV}$ infection due to the need of repeated blood transfusions for anemia (prior to the availability of blood product screening for $\mathrm{HCV}$ infection) [6] and hemodialysis (up to 91\%) [7-9]. Chronic HCV infection also seems to be associated with a higher prevalence of CKD and shorter renal survival, compared with controls [10]. Interferonbased treatments have been associated with severe adverse events for HCV-infected patients with CKD [2].

After the approval of direct-acting antiviral (DAA), treatment initiation in $\mathrm{HCV}$-infected patients with CKD seemed to be less likely in HCV genotype (GT) 2 or 3 and those with diabetes, cardiovascular disease, alcohol abuse or dependence or cirrhosis at baseline [11]. Because HCV NS5B 
inhibitor sofosbuvir, which also is effective for HCV GT 2 or 3 , has not been recommended for patients with severe renal impairment, and $\mathrm{HCV}$-infected patients with more advanced CKD and other complications are less likely to receive treatment for HCV.

Strategies are needed to improve the treatment for HCVinfected patients with renal impairment. In the present article, we discuss recent strategies with interferon-free treatments, which could result in higher sustained virologic response (SVR) rates, for $\mathrm{HCV}$-infected patients with CKD.

\section{Treatment for patients with HCV-related liver diseases, CKD stage 5 with/without hemodialysis and having renal transplant prospect}

In general, treatment in setting of kidney transplantation, timing of HCV treatment may be before kidney transplant and if therapy needed after kidney transplantation, careful attention should be paid to drug interactions with immunosuppressive agents. Treatment options for hepatitis $\mathrm{C}$ in presence of CKD also depend upon the possibility of renal transplant in near future as well as the severity of underlying liver disease. In patients with compensated $\mathrm{HCV}$-related liver disease, CKD stage 5 with/without hemodialysis and having renal transplant prospect, it is advisable to initiate antiviral therapy post renal transplantation.

CKD patients with HCV-related advanced cirrhosis [patients with clinical decompensation and/or hepatic venous pressure gradient $(\mathrm{HVPG})>10 \mathrm{mmHg}$ ] require combined liver-kidney transplantation, which is often not feasible, especially in living donor-related liver transplant (LRLT) settings and considering no other options, these patients should be treated with sofosbuvir-based regimens under close monitoring. This regimen may not be optimal for severe CKD which the guideline does not refute but it may be also too late for the underlying liver disease. Thus, this approach may be reserved for situations where also LRLT is not an option. However, when LRLT is an option such patients may be rescued by LRLT and post-transplant could have their advanced CKD managed by hemodialysis while receiving DAA treatment for non-cirrhotic post-transplant chronic hepatitis C. Although the previous study [12] has demonstrated that DAA treatment is safe and effective at post-kidney transplantation, it may be better for kidney transplantation candidates with HCV-related decompensated cirrhosis and CKD stage 4 or 5 to be treated with sofosbuvir-based regimens under close monitoring before transplantation. Because the patient receives a new kidney, any harm of a sofosbuvir based regimen on kidney function may be less important for kidney transplantation candidate. This approach may be an option in kidney transplantation candidates but not in liver transplantation candidates. Further study will be needed (Fig. 1).

Real-life data from the ongoing HCV-TARGET study have also demonstrated the efficacy of DAA therapy in patients with kidney transplant and in those with dual liver-kidney transplant. Various regimens were used, including sofosbuvir/ledipasvir with or without ribavirin (85\%); sofosbuvir plus daclatasvir with or without ribavirin (9\%); and ombitasvir/paritaprevir/ritonavir plus dasabuvir with or without ribavirin (6\%). The SVR12 rate was $94.6 \%$ in those with kidney transplant and $90.9 \%$ in dual liver-kidney transplant recipients [13].

\section{Classification of chronic kidney disease (CKD)}

The definition of CKD includes all cases with markers of kidney damage [albuminuria (albumin creatine ratio $>3 \mathrm{mg} /$ $\mathrm{mmol}$ ), hematuria (of presumed or confirmed renal origin), electrolyte abnormalities due to tubular disorders, renal histological abnormalities, structural abnormalities detected by imaging or a history of kidney transplantation] or those with an eGFR $<60 \mathrm{ml} / \mathrm{min} / 1.73 \mathrm{~m}^{2}$ on at least 2 occasions 90 days apart with or without markers of kidney damage [14]. In general, some patients who have undergone a kidney transplant or have CKD treated with immunosuppressive therapy and/or have anemia, are not always amenable to treatment with some direct-acting antivirals (DAAs) for HCV which is excreted through kidney [2, 15] (Table 1). It may be more appropriate to avoid the use of sofosbuvir or ribavirin in patients with GFR $<30 \mathrm{ml} / \mathrm{min} / 1.73 \mathrm{~m}^{2}$ or patients with a GFR $<50 \mathrm{ml} / \mathrm{min} / 1.73 \mathrm{~m}^{2}$, respectively.

$\mathbf{a}$

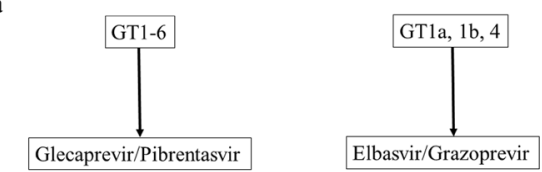

$\mathbf{b}$

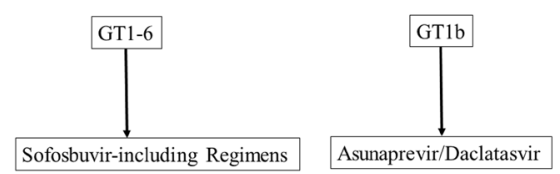

Fig. 1 APASL recommendation for the treatment regimens of patients with $\mathrm{HCV}$ and severe impaired renal function. a For glecaprevir/pibrentasvir and/or elbasvir/grazoprevir-affordable/available countries. b For glecaprevir/pibrentasvir and/or elbasvir/grazoprevirunaffordable/unavailable countries. Although several studies demonstrated that high SVR rate by asunaprevir and daclatasvir in patients with HCV genotype 1b (GT1b) with resistance-associated substitution (RAS) and renal impairment, this combination should be avoided in patients with HCV GT1b with RAS 
Table 1 Selection of DAA regimens based on renal function

\begin{tabular}{|c|c|c|c|c|c|}
\hline \multirow[t]{2}{*}{ DAAs } & \multicolumn{3}{|c|}{ Target of DAAs } & \multicolumn{2}{|l|}{ Metabolism } \\
\hline & NS3/4A & NS5A & NS5B & $\begin{array}{l}\text { Hepatic } \\
\text { metabolism/ } \\
\text { metabolites }\end{array}$ & $\begin{array}{l}\text { Renal } \\
\text { excretion }\end{array}$ \\
\hline Telaprevir & Yes & - & - & Yes & - \\
\hline Boceprevir & Yes & - & - & Yes & - \\
\hline Simeprevir & Yes & - & - & Yes & - \\
\hline Grazoprevir & Yes & - & - & Yes & - \\
\hline Asunaprevir & Yes & - & - & Yes & - \\
\hline Paritaprevir & Yes & - & - & Yes & - \\
\hline Glecaprevir & Yes & - & - & Yes & - \\
\hline Voxilaprevir & Yes & - & - & Yes & - \\
\hline Daclatasvir & - & Yes & - & Yes & - \\
\hline Ledipasvir & - & Yes & - & Yes & - \\
\hline Ombitasvir & - & Yes & - & Yes & - \\
\hline Elbasvir & - & Yes & - & Yes & - \\
\hline Pibrentasvir & - & Yes & - & Yes & - \\
\hline Velpatasvir & - & Yes & - & Yes & - \\
\hline Sofosbuvir $^{\mathrm{a}}$ & - & - & Yes & - & Yes \\
\hline Beclabuvir & - & - & Yes & Yes & - \\
\hline Ribavirin $^{\mathrm{b}}$ & - & - & - & - & Yes \\
\hline
\end{tabular}

$D A A s$, direct-acting antiviral agents

${ }^{a}$ Better to use in patients with eGFR $\geq 30 \mathrm{ml} / \mathrm{min} / 1.73 \mathrm{~m}^{2}$

${ }^{\mathrm{b}}$ Better to use in patients with eGFR $\geq 50 \mathrm{ml} / \mathrm{min} / 1.73 \mathrm{~m}^{2}$ and hemoglobin $\geq 12 \mathrm{~g} / \mathrm{dl}$

Thus, careful attention should be paid to the selection of DAAs for HCV-infected patients with renal impairment. We describe two regimens that are relatively safe and recommended for patients with CKD stages 4 and 5 .

\section{Selection of DAAs in HCV-infected patients with severe renal impairment}

\section{Treatment with a 12-week combination of grazoprevir/elbasvir for patients with HCV GT1a, GT1b or GT4}

The C-SURFFER study included a total of 224 HCV GT1 and stages 4 and 5 CKD patients: 111 and 113 patients who belong to immediate treatment and deferred treatment groups with HCV NS3/4A protease inhibitor grazoprevir (100 mg daily)/HCV NS5A inhibitor elbasvir (50 mg daily) for 12 weeks, respectively [16]. Of these patients, 179 (76\%) were hemodialysis-dependent, $122(52 \%)$ were infected with HCV GT1a, 189 (80\%) were HCV treatment-naïve, 14 (6\%) had cirrhosis, and 108 (46\%) were African American. SVR rates in the immediate treatment and deferred treatment groups with grazoprevir/elbasvir were 99\% (115/116) and
98\% (97/99), respectively [16]. Thus, grazoprevir/elbasvir could lead to higher SVR rates in patients with HCV GT1 and stages 4 and 5 CKD $[16,17]$. In the C-SURFFER study [16], the most common adverse events were headache, nausea and fatigue. Cardiac serious events (one cardiac arrest, one cardiomyopathy and three myocardial infarction) were reported in five cases [16]. Other serious adverse events reported in more than one patient were: hypotension, pneumonia, upper gastrointestinal hemorrhage, and aortic aneurysm [16].

Asselah et al. [18] demonstrated that, among HCV GT4infected patients treated with 12 or 16 weeks of grazoprevir/ elbasvir with or without ribavirin, the SVR12 rates in treatment-naïve and treatment-experienced (previously failed pegylated interferon-based treatment) were 96\% (107/111) and 89\% (39/44), respectively. Although HCV NS5A resistance-associated substitutions (RASs) emerged at virologic failure, baseline HCV NS5A RASs did not impact the SVR 12 rates in the 12 weeks arm of grazoprevir/elbasvir [18].

In patients with HCV GT1a, 1b or 4 and stage 4 or 5 $\mathrm{CKD}$, the use of elbasvir and grazoprevir without ribavirin are recommended by the American Association for the Study of Liver Diseases (AASLD) and Infectious Diseases Society of America (IDSA) [19].

\section{Treatment with a pangenotypic combination of glecaprevir/pibrentasvir for 8-16 weeks}

Gane et al. [20] reported that the HCV NS3/4A protease inhibitor glecaprevir combined with the HCV NS5A inhibitor pibrentasvir could result in 98\% (102/104) SVR rates in patients with HCV and severe renal impairment [CKD stage 4, 13\% (14 patients); CKD stage 5, 87\% (90 patients); and/ or hemodialysis, $82 \%$ (85 patients)]. Their study included a total of 104 patients [male, 76\% (79 patients); mean age, 57 years; and mean eGFR in patients not undergoing hemodialysis, $20.6 \mathrm{ml} / \mathrm{min} / 1.73 \mathrm{~m}^{2}$ ]. The numbers of HCV GT1a, GT1b, GT1 other subgenotypes, GT2, GT3, GT4, GT5 and GT6 were 23, 29, 2, 17, 11, 20, 1 and 1, respectively. The number of treatment-naïve and cirrhotic patients were 58\% (60 patients) and 19\% (20 patients), respectively. Common adverse events were pruritus (20\%), fatigue (14\%) and nausea (12\%) [20]. Serious adverse events were observed in $24 \%(25 / 104)$. One patient with hemodialysis and hypertension had a cerebral hemorrhage at 2 weeks post-end of treatments (EOT). One patient discontinued treatment at 2 weeks because of non-serious adverse events of diarrhea. Three additional patients discontinued treatments: one at week 8 due to pruritus; one at week 10 due to pulmonary edema, hypertensive cardiomyopathy and congestive heart failure; and one at week 12 due to a hypertensive crisis [20].

The combination of glecaprevir (300 mg daily)/pibrentasvir (120 mg daily) was shown to lead to high SVR rates 
in Japanese HCV GT1 or GT2-infected patients with severe renal impairment (eGFR $<30 \mathrm{ml} / \mathrm{min} / 1.73 \mathrm{~m}^{2}$ ) [21].

The use of glecaprevir/pibrentasvir without ribavirin is also recommended by the American Association for the Study of Liver Diseases (AASLD) and Infectious Diseases Society of America (IDSA) for the treatment of patients with HCV GT1, GT2, GT3, GT4, GT5, or GT6 and severe renal impairment [19].

\section{Treatment with a 24-week combination of asunaprevir/daclatasvir without ribavirin for HCV GT1b patients}

The combination of HCV NS3/4A protease inhibitor asunaprevir (200 mg daily) and HCV NS5A inhibitor daclatasvir (60 mg daily) for 24 weeks resulted in 100\% (16/16) and $100 \%(8 / 8)$ SVR rates in stages 3b, 4 and 5 CKD and HCV GT1b-patients, respectively [22]. This treatment combination also reportedly led to $96 \%$ (20/21) and $100 \%(28 / 28)$ SVR rates [23, 24]. Thus, a 24-week combination of asunaprevir/daclatasvir without ribavirin may be a treatment option for patients with HCV GT1b and severe renal impairment [25], although this regimen requires measurement of $\mathrm{HCV}$ GTs and HCV NS5A RASs before treatment [26].

\section{Selection of DAAs in HCV-infected patients with mild renal impairment}

\section{Sofosbuvir-based regimens in patients with HCV and renal impairment}

Sofosbuvir and/or ribavirin are excreted through the kidney, therefore, in general, it may be more appropriate to avoid the use of sofosbuvir or ribavirin in patients with CKD stage 3a, 3b, 4 or 5. However, it has been reported that
HCV NS5B inhibitor sofosbuvir-based regimens have been used for HCV-infected patients with severe renal impairment (Table 2) [27-29]. Patients with CKD stages 3b/4/5 (eGFR $<30 \mathrm{ml} / \mathrm{min} / 1.73 \mathrm{~m}^{2}$ ) or on hemodialysis seemed to tolerate sofosbuvir-based regimens well. Although sofosbuvir-based regimens could lead to higher SVR rates, sofosbuvir is converted into inactive metabolites and safe and effective doses of sofosbuvir in patients with an eGFR $<30 \mathrm{ml} /$ min have not been established [19]. Taneja et al. [27] reported that low-dose sofosbuvir and full-dose HCV NS5A inhibitor daclatasvir are safe and effective in treating patients with HCV and CKD stages 3b/4/5. Japanese study [30] demonstrated that SVR rates were $97.0,97.1$ and $94.7 \%$ and incidence rates of adverse events were $0,0.5$ and $3.0 \%$ in sofosbuvir/ledipasvir-treated HCV GT1b-patients with CKD stages 1,2 and 3, respectively. Although the half-daily dose of sofosbuvir and daclatasvir could also lead to $90.2 \%$ SVR rates in 41 patients with HCV GTs 1 and 3 patients and none had a relapse, 2 patients discontinued, and 3 patients died during treatment [31]. Sofosbuvir should be used with caution in patients with severe renal impairment (eGFR $<30 \mathrm{ml} /$ $\mathrm{min} / 1.73 \mathrm{~m}^{2}$ ) without other treatment options, as the pharmacokinetics and safety of sofosbuvir derived metabolites under these circumstances are still being ascertained [32]. In general, sofosbuvir (400 mg daily) may be recommended for patients with CKD stages 1/2/3 (recommendation B-2 [15]). Generic sofosbuvir and branded sofosbuvir play a role in the elimination of $\mathrm{HCV}$ worldwide [28].

\section{Drug-drug interactions (DDIs) in patients with renal impairment}

The rate of DDIs in patients who suffer from CKD is significant [33]. Comorbidity and polypharmacy are common in CKD-patients [34]. Most of DDAs have DDIs with some

Table 2 Sofosbuvir-based regimens in patients with HCV and renal impairment

\begin{tabular}{|c|c|c|c|c|c|c|}
\hline Ref. & GTs & No. of patients & CKD & $\begin{array}{l}\text { Treatment-naïve/cir- } \\
\text { rhosis }\end{array}$ & Regimens & SVR12 \\
\hline Taneja et al. [27] & $\begin{array}{l}\text { GT1, } 42(65 \%) ; \\
\text { GT2, 1 (1\%); } \\
\text { GT3, } 22(34 \%)\end{array}$ & 65 & $\begin{array}{l}\text { eGFR }<30 ; \mathrm{HD}, 54 \\
\quad(83 \%)\end{array}$ & $55(85 \%) / 21(32 \%)$ & $\begin{array}{l}\text { 12- or 24-week of } \\
200 \mathrm{mg} \mathrm{SOF} / 60 \mathrm{mg} \\
\text { DCV }\end{array}$ & $100 \%(65 / 65)$ \\
\hline Kumar et al. [28] & $\begin{array}{l}\text { GT1a, 17; GT1b, } \\
\text { 1; GT3a, 7; } \\
\text { GT3b, } 1\end{array}$ & 26 & $\begin{array}{l}\text { CKD stage } 4,5 \text { or HD } \\
(\text { eGFR }<30)\end{array}$ & $19(73 \%) / 22(85 \%)$ & $\begin{array}{l}\text { 24-Week of generic } \\
\text { SOF/RBV }\end{array}$ & $100 \%(26 / 26)$ \\
\hline Kumar et al. [28] & GT1a, 22; GT1b, 4 & 26 & $\begin{array}{l}\text { CKD stage } 4,5 \text { or HD } \\
(\text { eGFR }<30)\end{array}$ & $23(89 \%) / 20(77 \%)$ & $\begin{array}{l}\text { 12-Week of generic } \\
\text { SOF/LDV }\end{array}$ & $100 \%(26 / 26)$ \\
\hline Kumar et al. [28] & GT3a, 17; GT3b, 2 & 19 & $\begin{array}{l}\text { CKD stage } 4,5 \text { or HD } \\
(\text { eGFR }<30)\end{array}$ & $16(84 \%) / 12(63 \%)$ & $\begin{array}{l}\text { 12-Week of generic } \\
\text { SOF/DCV }\end{array}$ & $100 \%(19 / 19)$ \\
\hline Sho et al. [29] & GT2 & 40 & CKD stage $3 a / 3 b$ & $29(73 \%) / \mathrm{NA}$ & 12-Week of SOF/RBV & $90 \%(36 / 40)$ \\
\hline
\end{tabular}

Ref. reference, GTs genotypes, No number, CKD chronic kidney disease, $H D$ hemodialysis, eGFR estimated glomerular filtration rate, SVR12 sustained virological response at 12 weeks, $S O F$ sofosbuvir, $D C V$ daclatasvir, $L D V$ ledipasvir, $R B V$ ribavirin, $N A$ not available 
cardiovascular drugs [35]. Some statins are not recommended for concomitant use with glecaprevir/pibrentasvir treatment [36]. There is a high rate of clinically significant DDIs between DAAs and anti-epileptic medications [37]. During treatment with DAAs, which are even metabolized by the liver, careful management of DDIs should be required in $\mathrm{HCV}$-infected patients with CKD, who are using cardiovascular drugs, statins or anti-epileptic medications. Frequently encountered DDIs in the setting of CKD are shown in Suppl. Table 2.

\section{Conclusion}

$\mathrm{HCV}$ infection is usually asymptomatic in patients with endstage renal disease [38]; however, it may lead to decompensated liver diseases and HCC. In some patients with HCV infection and severe renal impairment, treatment with DAAs is discontinued due to renal dysfunction [39]. For patients with CKD stages $4 / 5$, hemodialysis should be prepared if renal function worsens and treatment with a DAA combination is initiated. In some patients undergoing hemodialysis, treatment with a DAA combination may be safer than those with CKD stages 4/5.

Recommendations for the treatment of patients with HCV and severe renal impairment are shown in Tables 3 and 4. A combination of elbasvir/grazoprevir is recommended for patients with HCV GT1a, 1b or 4 and stage 4 or 5 CKD [40]. A combination of glecaprevir/pibrentasvir is recommended for patients with HCV all GTs and stage 4 or 5 CKD (Table 3). Sofosbuvir-based regimens may be suitable for HCV-infected patients with mild renal impairment [28]. It has been reported that a higher frequency of anemia, worsening renal dysfunction and more severe adverse events were observed in patients with low baseline renal function [41]. To eliminate $\mathrm{HCV}$ worldwide, HCV-infected patients with renal impairment should be treated with these combination therapies.

Funding None.

Table 3 APASL recommendation for the treatment regimens of patients with HCV and severe impaired renal function

\begin{tabular}{|c|c|c|c|}
\hline HCV GTs & Regimens & $\begin{array}{l}\text { Treatment } \\
\text { duration } \\
\text { (weeks) }\end{array}$ & $\begin{array}{l}\text { Grading of evidence and recom- } \\
\text { mendations (disease status) }\end{array}$ \\
\hline GT1a, GT1b, GT4 & Elbasvir (50 mg daily)/grazoprevir (100 mg daily) & 12 & A-1 (CKD 3b/4/5 or hemodialysis) \\
\hline All GTs & Glecaprevir (300 mg daily)/pibrentasvir (120 mg daily) & $8-16$ & A-1 (CKD 3b/4/5 or hemodialysis) \\
\hline GT1b & Daclatasvir (60 mg daily)/asunaprevir (200 mg daily) & 24 & B-2 (CKD 3b/4/5 or hemodialysis) \\
\hline All GTs & $\begin{array}{l}\text { Sofosbuvir (400 mg daily)/daclatasvir ( } 60 \mathrm{mg} \text { daily) under close moni- } \\
\text { toring }\end{array}$ & 12 & B-2 (CKD 3b/4/5 or hemodialysis) \\
\hline GT1 & $\begin{array}{l}\text { Sofosbuvir (400 mg daily)/ledipasvir (90 mg daily) under close moni- } \\
\text { toring }\end{array}$ & 12 & B-2 (CKD 3b/4/5 or hemodialysis) \\
\hline
\end{tabular}

Grading of evidence and recommendations are shown in Suppl. Table 1

GTs genotypes

Table 4 Treatment regimens for patients with hepatitis C virus infection and severe renal impairment: APASL recommendation (this article), compared with those of EASL [32] or AASLD-IDSA [19]

\begin{tabular}{|c|c|c|c|}
\hline Regimens & APASL & EASL & AASLD-IDSA \\
\hline Elbasvir/grazoprevir & $\begin{array}{l}\text { A-1 [CKD 3b/4/5 or hemodialysis } \\
(\mathrm{GT} 1 \mathrm{a}, 1 \mathrm{~b}, 4)]\end{array}$ & $\begin{array}{l}\text { A-1 [CKD 3b/4/5 or hemodialysis } \\
\text { (GT1b)] }\end{array}$ & $\begin{array}{l}\text { B-1 [CKD 3b/4/5 or hemodialysis } \\
\text { (GT1a, 1b, 4)] }\end{array}$ \\
\hline Glecaprevir/pibrentasvir & $\begin{array}{l}\text { A-1 [CKD } 3 \mathrm{~b} / 4 / 5 \text { or hemodialysis } \\
\text { (all GTs)] }\end{array}$ & $\begin{array}{l}\text { A-1 [CKD 3b/4/5 or hemodialysis } \\
\text { (all GTs)] }\end{array}$ & $\begin{array}{l}\text { B-1 [CKD } 3 \mathrm{~b} / 4 / 5 \text { or hemodialysis (all } \\
\text { GTs)] }\end{array}$ \\
\hline Daclatasvir/asunaprevir & $\begin{array}{l}\text { B-2 [CKD } 3 \mathrm{~b} / 4 / 5 \text { or hemodialysis } \\
\text { (GT1b)] }\end{array}$ & No description & No description \\
\hline Sofosbuvir-based regimens & $\begin{array}{l}\text { B-2 [CKD } 4 / 5 \text { or hemodialysis (all } \\
\text { GTs)] }\end{array}$ & B-1 (alternative treatment) & $\begin{array}{l}\text { Not recommendation and need close } \\
\text { monitoring [41] }\end{array}$ \\
\hline $\begin{array}{l}\text { Ritonavir-boosted } \\
\text { paritaprevir/ombitasvir/ } \\
\text { dasabuvir }\end{array}$ & No description & $\begin{array}{l}\text { A-1 [CKD } 3 b / 4 / 5 \text { or hemodialysis } \\
\text { (GT1b)] }\end{array}$ & No description \\
\hline
\end{tabular}

Grading of evidence and recommendations are shown in Suppl. Table 1

GTs genotypes, $C K D$ chronic kidney disease 


\section{Compliance with ethical standards}

Conflict of interest Dr. Tatsuo Kanda received research grants from Merck Sharp and Dohme (MSD), Chugai Pharm and AbbVie. The founding sponsors played no role in the study design, data collection, analyses, interpretation, writing of the manuscript, or in the decision to publish the results. George K. K. Lau, Lai Wei, Mitsuhiko Moriyama, Ming-Lung Yu, Wang-Long Chuang, Alaaeldin Ibrahim, Cosmas Rinaldi Adithya Lesmana, Jose Sollano, Manoj Kumar, Ankur Jindal, Barjesh Chander Sharma, Saeed S. Hamid, A. Kadir Dokmeci, Mamun-Al-Mahtab, Geofferey W. McCaughan, Jafri Wasim, Darrell H. G. Crawford, Jia-Horng Kao, Osamu Yokosuka, Shiv Kumar Sarin, Masao Omata have declared that there are no conflicts of interest.

Ethical approval This article does not contain any studies with human participants or animals performed by any of authors.

Informed consent Not necessary, see above.

Open Access This article is distributed under the terms of the Creative Commons Attribution 4.0 International License (http://creativeco mmons.org/licenses/by/4.0/), which permits unrestricted use, distribution, and reproduction in any medium, provided you give appropriate credit to the original author(s) and the source, provide a link to the Creative Commons license, and indicate if changes were made.

\section{References}

1. Kanda T, Imazeki F, Yokosuka O. New antiviral therapies for chronic hepatitis C. Hepatol Int 2010;4:548-561

2. Omata M, Kanda T, Yu ML, Yokosuka O, Lim SG, Jafri W, et al. APASL consensus statements and management algorithms for hepatitis C virus infection. Hepatol Int 2012;6:409-435

3. Mayo MJ. Extrahepatic manifestations of hepatitis $\mathrm{C}$ infection. Extrahepatic manifestations of hepatitis $\mathrm{C}$ infection. Am J Med Sci 2003;325:135-148

4. Charles ED, Dustin LB. Hepatitis C virus-induced cryoglobulinemia. Kidney Int 2009;76:818-824

5. Fabrizi F, Dixit V, Martin P, Messa P. The evidence-based epidemiology of $\mathrm{HCV}$-associated kidney disease. Int J Artif Organs 2012;35:621-628

6. Takano S, Omata M, Ohto M, Satomura Y. Prospective assessment of donor blood screening for antibody to hepatitis $\mathrm{C}$ virus and high-titer antibody to $\mathrm{HBcAg}$ as a means of preventing posttransfusion hepatitis. Hepatology 1993;18:235-239

7. Zeldis JB, Depner TA, Kuramoto IK, Gish RG, Holland PV. The prevalence of hepatitis $\mathrm{C}$ virus antibodies among hemodialysis patients. Ann Intern Med 1990;112:958-960

8. Okuda K, Hayashi H, Kobayashi S, Irie Y. Mode of hepatitis C infection not associated with blood transfusion among chronic hemodialysis patients. J Hepatol 1995;23:28-31

9. Okuda K, Yokosuka O. Natural history of chronic hepatitis $\mathrm{C}$ in patients on hemodialysis: case control study with 4-23 years of follow-up. World J Gastroenterol 2004;10:2209-2212

10. Satapathy SK, Lingisetty CS, Williams S. Higher prevalence of chronic kidney disease and shorter renal survival in patients with chronic hepatitis C virus infection. Hepatol Int 2012;6:369-378

11. Butt AA, Ren Y, Puenpatom A, Arduino JM, Kumar R, AbouSamra AB. HCV treatment initiation in persons with chronic kidney disease in the directly acting antiviral agents era: results from ERCHIVES. Liver Int 2018;38:1411-1417
12. Sasaki R, Kanda T, Yasui S, Haga Y, Nakamura M, Yamato M, et al. Successful eradication of hepatitis $\mathrm{C}$ virus by interferon-free regimens in two patients with advanced liver fibrosis following kidney transplantation. Case Rep Gastroenterol 2016;10:248-256

13. Saxena V, Khungar V, Verna EC, Levitsky J, Brown RS, Hassan MA, et al. Safety and efficacy of current direct-acting antiviral regimens in kidney and liver transplant recipients with hepatitis C: results from the HCV-TARGET study. Hepatology 2017;66:1090-1101

14. Kidney Disease: Improving Global Outcomes (KDIGO) CKD Work Group. KDIGO. Clinical practice guideline for the evaluation and management of chronic kidney disease. Kidney Int Suppl 2012;2013(3):19-62

15. Omata M, Kanda T, Wei L, Yu ML, Chuang WL, Ibrahim A, et al. APASL consensus statements and recommendation on treatment of hepatitis C. Hepatol Int 2016;10:702-726

16. Roth D, Nelson DR, Bruchfeld A, Liapakis A, Silva M, Monsour $\mathrm{H} \mathrm{Jr}$, et al. Grazoprevir plus elbasvir in treatment-naive and treatment-experienced patients with hepatitis $\mathrm{C}$ virus genotype 1 infection and stage 4-5 chronic kidney disease (the C-SURFER study): a combination phase 3 study. Lancet 2015;386:1537-1545

17. Bruchfeld A, Roth D, Martin P, Nelson DR, Pol S, Londoño MC, et al. Elbasvir plus grazoprevir in patients with hepatitis $C$ virus infection and stage 4-5 chronic kidney disease: clinical, virologi$\mathrm{cal}$, and health-related quality-of-life outcomes from a phase 3 , multicentre, randomised, double-blind, placebo-controlled trial. Lancet Gastroenterol Hepatol 2017;2:585-594

18. Asselah T, Reesink H, Gerstoft J, de Ledinghen V, Pockros PJ, Robertson M, et al. Efficacy of elbasvir and grazoprevir in participants with hepatitis $\mathrm{C}$ virus genotype 4 infection: a pooled analysis. Liver Int 2018;38:1583-1591

19. AASLD-IDSA HCV guidance: recommendations for testing, managing, and treating hepatitis C. https://www.hcvguidelines. org. Accessed 18 June 2018

20. Gane E, Lawitz E, Pugatch D, Papatheodoridis G, Bräu N, Brown A, et al. Glecaprevir and pibrentasvir in patients with $\mathrm{HCV}$ and severe renal impairment. N Engl J Med 2017;377:1448-1455

21. Kumada H, Watanabe T, Suzuki F, Ikeda K, Sato K, Toyoda H, et al. Efficacy and safety of glecaprevir/pibrentasvir in HCVinfected Japanese patients with prior DAA experience, severe renal impairment, or genotype 3 infection. J Gastroenterol 2018;53:566-575

22. Suda G, Nagasaka A, Yamamoto Y, Furuya K, Kumagai K, Kudo $M$, et al. Safety and efficacy of daclatasvir and asunaprevir in hepatitis $\mathrm{C}$ virus-infected patients with renal impairment. Hepatol Res 2017;47:1127-1136

23. Suda G, Kudo M, Nagasaka A, Furuya K, Yamamoto Y, Kobayashi T, et al. Efficacy and safety of daclatasvir and asunaprevir combination therapy in chronic hemodialysis patients with chronic hepatitis C. J Gastroenterol 2016;51:733-740

24. Toyoda H, Kumada T, Tada T, Takaguchi K, Ishikawa T, Tsuji $\mathrm{K}$, et al. Safety and efficacy of dual direct-acting antiviral therapy (daclatasvir and asunaprevir) for chronic hepatitis $\mathrm{C}$ virus genotype 1 infection in patients on hemodialysis. J Gastroenterol 2016;51:741-747

25. Suda G, Furusyo N, Toyoda H, Kawakami Y, Ikeda H, Suzuki M, et al. Daclatasvir and asunaprevir in hemodialysis patients with hepatitis $\mathrm{C}$ virus infection: a nationwide retrospective study in Japan. J Gastroenterol 2018;53:119-128

26. Kanda T, Yasui S, Nakamura M, Suzuki E, Arai M, Haga Y, et al. Daclatasvir plus asunaprevir treatment for real-world HCV genotype 1-infected patients in Japan. Int J Med Sci 2016;13:418-423

27. Taneja S, Duseja A, De A, Mehta M, Ramachandran R, Kumar V, et al. Low-dose sofosbuvir is safe and effective in treating chronic 
hepatitis $\mathrm{C}$ in patients with severe renal impairment or end-stage renal disease. Dig Dis Sci 2018;63:1334-1340

28. Kumar M, Nayak SL, Gupta E, Kataria A, Sarin SK. Generic sofosbuvir-based direct-acting antivirals in hepatitis $\mathrm{C}$ virusinfected patients with chronic kidney disease. Liver Int 2018. https ://doi.org/10.1111/liv.13863 (Epub ahead of print)

29. Sho T, Suda G, Nagasaka A, Yamamoto Y, Furuya K, Kumagai K, et al. Safety and efficacy of sofosbuvir and ribavirin for genotype 2 hepatitis C Japanese patients with renal dysfunction. Hepatol Res 2018;48:529-538

30. Okubo T, Atsukawa M, Tsubota A, Toyoda H, Shimada N, Abe $\mathrm{H}$, et al. Efficacy and safety of ledipasvir/sofosbuvir for genotype $1 \mathrm{~b}$ chronic hepatitis $\mathrm{C}$ patients with moderate renal impairment. Hepatol Int 2018;12:133-142

31. Goel A, Bhadauria DS, Kaul A, Verma P, Mehrotra M, Gupta A, et al. Daclatasvir and reduced-dose sofosbuvir: an effective and pangenotypic treatment for hepatitis $\mathrm{C}$ in patients with eGFR < $30 \mathrm{ml} / \mathrm{min}$. Nephrology (Carlton). 2018. https://doi.org/10.1111/ nep.13222 (Epub ahead of print)

32. European Association for the Study of the Liver. EASL recommendations on treatment of hepatitis C 2018. J Hepatol 2018;69:461-511

33. Sharifi H, Hasanloei MA, Mahmoudi J. Polypharmacy-induced drug-drug interactions; threats to patient safety. Drug Res (Stuttg) 2014;64:633-637

34. Fraser SD, Taal MW. Multimorbidity in people with chronic kidney disease: implications for outcomes and treatment. Curr Opin Nephrol Hypertens 2016;25:465-472
35. University of Liverpool. HEP drug interactions. http://www.hepdruginteractions.org. Accessed 7 Aug 2018

36. Kwo P, Jones P, Barcomb L, Gathe J Jr, Yu Y, Dylla D, et al. Safety and efficacy of statin management during glecaprevir/ pibrentasvir treatment for chronic hepatitis C. J Am Coll Cardiol 2018;71(suppl):A1763

37. Coghlan M. Hepatitis $\mathrm{C}$ direct-acting anti-viral treatment options in patients with epilepsy. A drug-drug interaction dilemma in hepatitis C infection. In: AASLD liver meeting 2017: abstract final ID: 1583

38. Arora A, Bansal N, Sharma P, Singla V, Gupta V, Tyagi P, et al. Hepatitis $C$ virus infection in patients with end-stage renal disease: a study from a tertiary care centre in India. J Clin Exp Hepatol 2016;6:21-25

39. Kanda T, Yasui S, Nakamura M, Nakamoto S, Takahashi K, Wu $S$, et al. Successful retreatment with grazoprevir and elbasvir for patients infected with hepatitis $C$ virus genotype $1 \mathrm{~b}$, who discontinued prior treatment with NS5A inhibitor-including regimens due to adverse events. Oncotarget 2018;9:16263-16270

40. Kramer JR, Puenpatom A, Erickson K, Cao Y, Smith D, El-Serag $\mathrm{H}$, et al. Real-world effectiveness of elbasvir/grazoprevir in HCVinfected patients in the US veterans affairs healthcare system. J Viral Hepat 2018;25:1270-1279

41. Saxena V, Koraishy FM, Sise ME, Lim JK, Schmidt M, Chung RT, et al. Safety and efficacy of sofosbuvir-containing regimens in hepatitis $\mathrm{C}$-infected patients with impaired renal function. Liver Int 2016;36:807-816

\section{Affiliations}

Tatsuo Kanda ${ }^{1}$ - George K. K. Lau ${ }^{2} \cdot$ Lai Wei $^{3}$ - Mitsuhiko Moriyama ${ }^{1}$ Ming-Lung Yu ${ }^{4,5}$. Wang-Long Chuang ${ }^{5}$. Alaaeldin Ibrahim $^{6} \cdot$ Cosmas Rinaldi Adithya Lesmana $^{7,8}$. Jose Sollano ${ }^{9} \cdot$ Manoj Kumar $^{10}$. Ankur Jindal ${ }^{10}$. Barjesh Chander Sharma ${ }^{11}$. Saeed S. Hamid ${ }^{12}$. A. Kadir Dokmeci ${ }^{13} \cdot$ Mamun-Al-Mahtab $^{14}$. Geofferey W. McCaughan ${ }^{15}$. Jafri Wasim ${ }^{12}$. Darrell H. G. Crawford ${ }^{16}$. Jia-Horng Kao ${ }^{17}$. Osamu Yokosuka ${ }^{18}$. Shiv Kumar Sarin ${ }^{10} \cdot$ Masao Omata $^{19,20}$

1 Division of Gastroenterology and Hepatology, Department of Medicine, Nihon University School of Medicine, Tokyo, Japan

2 Humanity and Health Medical Center, Hong Kong, SAR, China

3 Peking University People's Hospital, Peking University Hepatology Institute, Beijing, China

4 Kaohsiung Municipal Ta-Tung Hospital, Kaohsiung, Taiwan

5 Hepatobiliary Division, Department of Internal Medicine, Kaohsiung Medical University Hospital, Kaohsiung Medical University, Kaohsiung, Taiwan

6 GI/Liver Division, Department of Internal Medicine, University of Benha, Benha, Egypt

7 Digestive Disease and GI Oncology Centre, Medistra Hospital, Jakarta, Indonesia

8 Hepatobiliary Division, Department of Internal Medicine, Dr. Cipto Mangunkusumo Hospital, Universitas Indonesia, Jakarta, Indonesia

9 University Santo Tomas Hospital, Manila, Philippines

10 Department of Hepatology, Institute of Liver and Biliary Sciences, New Delhi, India
11 Department of Gastroenterology, G.B. Pant Hospital, New Delhi, India

12 Department of Medicine, Aga Khan University and Hospital, Stadium Road, Karachi 74800, Pakistan

13 Department of Gastroenterology, Ankara University School of Medicine, Ankara, Turkey

14 Department of Hepatology, Bangabandhu Sheikh Mujib Medical University, Dhaka 1000, Bangladesh

15 Royal Prince Alfred Hospital, Centenary Institute, University of Sydney, Sydney, Australia

16 School of Medicine, University of Queensland, Woolloongabba, QLD 4102, Australia

17 National Taiwan University College of Medicine and National Taiwan University Hospital, Taipei, Taiwan

18 Graduate School of Medicine, Chiba University, Chiba, Japan

19 Yamanashi Prefectural Central Hospital, 1-1-1 Fujimi, Kofu-shi, Yamanashi 400-8506, Japan

20 The University of Tokyo, 7-3-1 Hongo, Bunkyo-ku, Tokyo 113-8655, Japan 